\title{
Enantioselective Synthesis of 4- and 6-Azaindolines by a Cation- Directed Cyclization
}

\author{
Alan D. Lamb, Peter D. Davey, Russell W. Driver, Amber L. Thompson, and Martin D. Smith* \\ Chemistry Research Laboratory, University of Oxford, 12 Mansfield Road, Oxford, OX1 3TA, U.K.
}

Supporting Information

ABSTRACT: Functionalized 4- and 6-azaindolines are accessible with high levels of enantioselectivity by the cationdirected cyclization of aminopyridine-derived imines via phasetransfer catalysis. The extension of this methodology to diastereoselective cyclizations is also described.

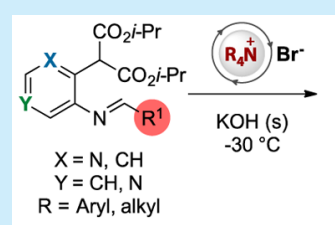

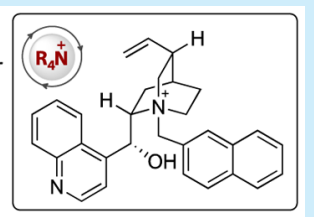

A

$\mathrm{s}$ a bioisostere of the indoline moiety, azaindolines represent attractive synthetic targets which are often incorporated into pharmaceutically active compounds. ${ }^{1}$ Relatively few general procedures exist for their synthesis, ${ }^{2}$ with the majority of methods directed toward the preparation of 5- or 7azaindolines. Reports of 4-azaindolines are particularly scarce, ${ }^{3}$ with existing synthetic routes involving base-mediated nucleophilic attack of nitrogen onto tosylates, ${ }^{1 a}$ acid catalyzed $\mathrm{N}$-cyclization onto alkenyl intermediates, ${ }^{4}$ intramolecular carbolithiation, ${ }^{5}$ palladium-catalyzed $\mathrm{C}-\mathrm{H}$ activation, ${ }^{6}$ or radical cyclization. ${ }^{2 g, 7}$ Moreover, to the best of our knowledge, only two enantioselective syntheses of azaindolines have been reported to date. ${ }^{6 \mathrm{~b}, 8}$

Cation-directed enantioselective cyclizations have previously been employed in the synthesis of indolines, indanes, and complex polycyclic systems, ${ }^{9-11}$ and we envisaged that this approach could be extended to encompass the preparation of a series of enantioenriched azaindoline scaffolds. The feasibility of this transformation was investigated through the cyclization of imine 1, which was prepared in three simple steps. ${ }^{12}$ An initial attempt at cyclization using aqueous potassium carbonate under phase-transfer conditions in the presence of $N$-benzylcinchonidinium chloride 3 led to a promising 90:10 er at room temperature (Table 1). Attempts to lower the temperature of the reaction to improve enantioselectivity resulted in reduced reactivity and poor conversion of starting material. However, a switch to solid bases resulted in smooth conversion to the desired azaindoline $\mathbf{2}$ at lower temperatures, with solid $\mathrm{KOH}$ at $-30{ }^{\circ} \mathrm{C}$ proving to be the optimum base (93:7 er). We subsequently evaluated several cinchonine-derived ammonium salts as catalysts, initially focusing on tuning the $\mathrm{N}$-substituent. Catalyst 4, bearing a 9-anthracenylmethyl group, gave an increased er (95:5), and N-2-naphthylmethyl cinchonidinium bromide 5 afforded the desired azaindoline in 97:3 er. We also varied the electronic properties of the pendant $\mathrm{N}$-benzylic group (as in 4-methoxy catalyst 6 and 4-trifluoromethyl catalyst 7 ), but this resulted in no increase in enantioselectivity over catalyst 5 (93:7 er vs 92:8 er respectively). With optimized conditions for the 6-azaindoline cyclization in hand, the scope of this transformation was then investigated (Figure 1). The
Table 1. Reaction Optimization ${ }^{a}$
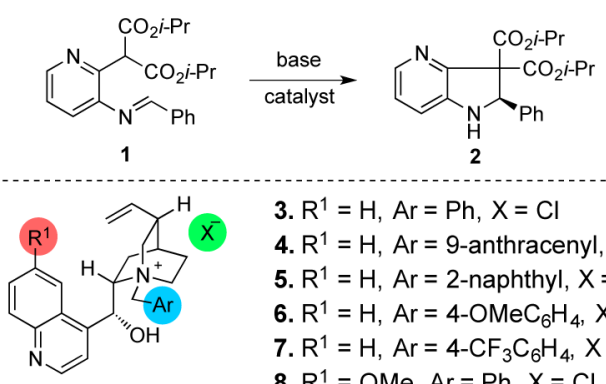

3. $\mathrm{R}^{1}=\mathrm{H}, \mathrm{Ar}=\mathrm{Ph}, \mathrm{X}=\mathrm{Cl}$

4. $\mathrm{R}^{1}=\mathrm{H}, \mathrm{Ar}=9$-anthracenyl, $X=\mathrm{Cl}$

5. $\mathrm{R}^{1}=\mathrm{H}, \mathrm{Ar}=$ 2-naphthyl, $\mathrm{X}=\mathrm{Br}$

6. $\mathrm{R}^{1}=\mathrm{H}, \mathrm{Ar}=4-\mathrm{OMeC}_{6} \mathrm{H}_{4}, X=\mathrm{Cl}$

7. $\mathrm{R}^{1}=\mathrm{H}, \mathrm{Ar}=4-\mathrm{CF}_{3} \mathrm{C}_{6} \mathrm{H}_{4}, \mathrm{X}=\mathrm{Br}$

8. $\mathrm{R}^{1}=\mathrm{OMe}, \mathrm{Ar}=\mathrm{Ph}, \mathrm{X}=\mathrm{Cl}$

\begin{tabular}{lccl}
\multicolumn{1}{c}{ base } & catalyst & temp, ${ }^{\circ} \mathrm{C}$ & \multicolumn{1}{c}{ er } \\
$\mathrm{K}_{2} \mathrm{CO}_{3}$ (aq.) & 3 & $\mathrm{rt}$ & $(+) 90: 10$ \\
$\mathrm{~K}_{2} \mathrm{CO}_{3}$ (aq.) & 3 & -15 & $\mathrm{nr}$ \\
$\mathrm{CsOH} \cdot \mathrm{H}_{2} \mathrm{O}(\mathrm{s})$ & 3 & -15 & $(+) 73: 27$ \\
$\mathrm{KOH}(\mathrm{s})$ & 3 & -15 & $(+) 88: 12$ \\
$\mathrm{KOH}(\mathrm{s})$ & 3 & -30 & $(+) 93: 7$ \\
$\mathrm{KOH}(\mathrm{s})$ & 4 & -30 & $(+) 95: 5$ \\
$\mathrm{KOH}(\mathrm{s})$ & 5 & -30 & $(+) 97: 3$ \\
$\mathrm{KOH}(\mathrm{s})$ & 6 & -30 & $(+) 93: 7$ \\
$\mathrm{KOH}(\mathrm{s})$ & 7 & -30 & $(+) 92: 8$ \\
$\mathrm{KOH}(\mathrm{s})$ & 8 & -30 & $(+) 92: 8$
\end{tabular}

${ }^{a}$ Conditions: 1.0 equiv of base, $10 \mathrm{~mol} \%$ catalyst, $3: 1$ toluene/ $\mathrm{CH}_{2} \mathrm{Cl}_{2}$. Er determined by chiral stationary phase HPLC; $(+)$ refers to sign of the optical rotation; $\mathrm{nr}=$ no reaction.

reaction is compatible with a range of substituted aryl imines, with high enantioselectivities observed with ortho- and parasubstituted aromatic substrates. ${ }^{13}$ For instance, ortho-substituted substrates 9, 10, and 11 cyclize in high er (98:2, 93:7, and 97:3 er respectively). Para-substituted substrates cyclize equally effectively ( $p$-chloro 12 94:6 er, p-bromo 13 94:6 er, $p$-nitro 14 95:5 er). A substrate bearing an electron-withdrawing group in the meta- position affords product $\mathbf{1 5}$ with only moderate er; however, an electron-donating substituent in the same position is well tolerated in the case of $\mathbf{1 6}$ (95:5 er).

Received: September 12, 2016

Published: October 6, 2016 

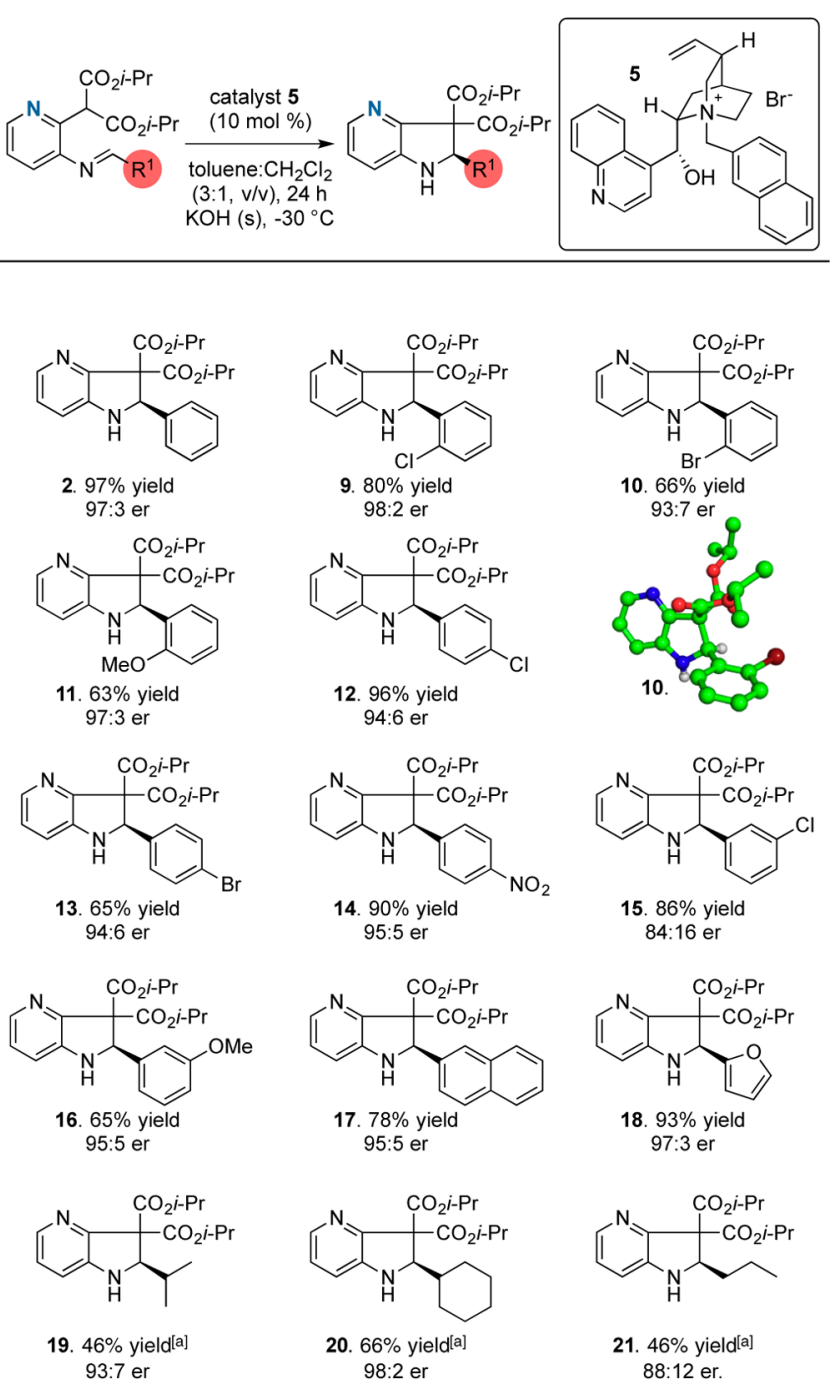

20. $66 \%$ yield[a] $98: 2$ er

demonstrated by $\mathbf{2 2}$ (90:10 er) and $\mathbf{2 3}$ (84:16 er) were similar to those observed in the 4-azaindoline system (Figure 2).

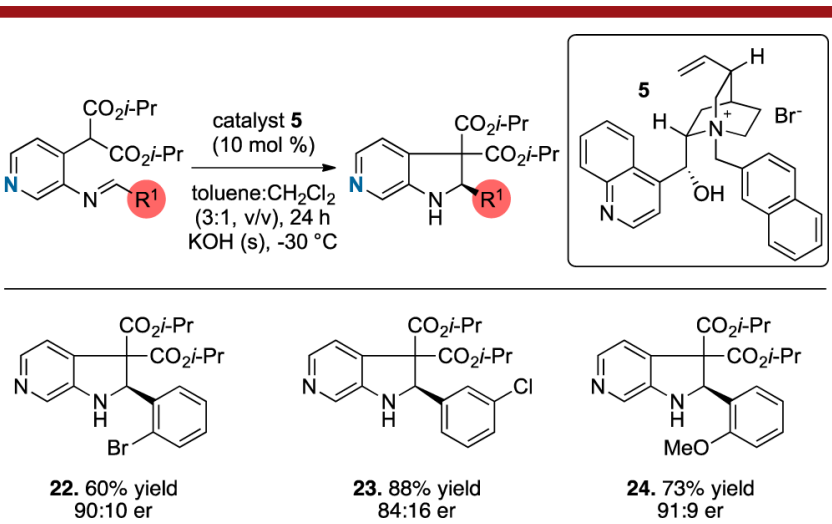

Figure 2. Cyclizations of 6-azaindolines. Yields are for isolated materials; er determined by chiral stationary phase HPLC.

It was possible to isolate an anisaldehyde-derived imine, albeit in low yield. The observed er for cyclization of this substrate to generate $\mathbf{2 4}$ was slightly lower (er 91:9) than the corresponding 4-azaindoline substrate 15 (er 97:3).

We have previously demonstrated that substrates which contain distinct electron-withdrawing groups rather than two isopropyl esters can cyclize to form indoline products containing two contiguous stereocenters, one of which is an all-carbon quaternary center. ${ }^{9,18}$ These cyclizations can proceed with excellent diastereoselectivity, and we rationalized that this would form an attractive route to stereochemically complex azaindolines (Scheme 1).

Scheme 1. Diastereoselective Cyclization ${ }^{a}$

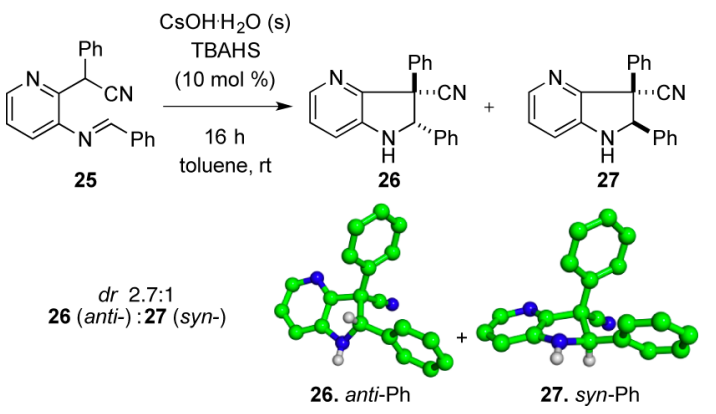

${ }^{a}$ Dr determined by ${ }^{1} \mathrm{H}$ NMR spectroscopy of the crude reaction mixture.

We synthesized a suitable substrate 25 to probe the potential for diastereo- and enantioselective cyclization with a chiral but racemic $\alpha$-aryl acetonitrile substituent, rather than the malonate derivative previously employed. Treatment of imine 25 with $\mathrm{CsOH} \cdot \mathrm{H}_{2} \mathrm{O}$ in the presence of tetra- $n$-butylammonium hydrogensulfate (TBAHS) resulted in complete conversion of starting material and the formation of a mixture of diastereomers, which were separated by chromatography and analyzed by single crystal X-ray diffraction to determine their relative stereochemistry. Under these conditions the reaction favored formation of the diastereomer 26 with the phenyl groups in an anti- relationship in 2.7:1 dr. The reaction was then attempted utilizing the previously optimized conditions in the presence of a chiral phase-transfer catalyst (Table 2). 
Table 2. Attempted Diastereo- and Enantioselective Cyclizations $^{a}$

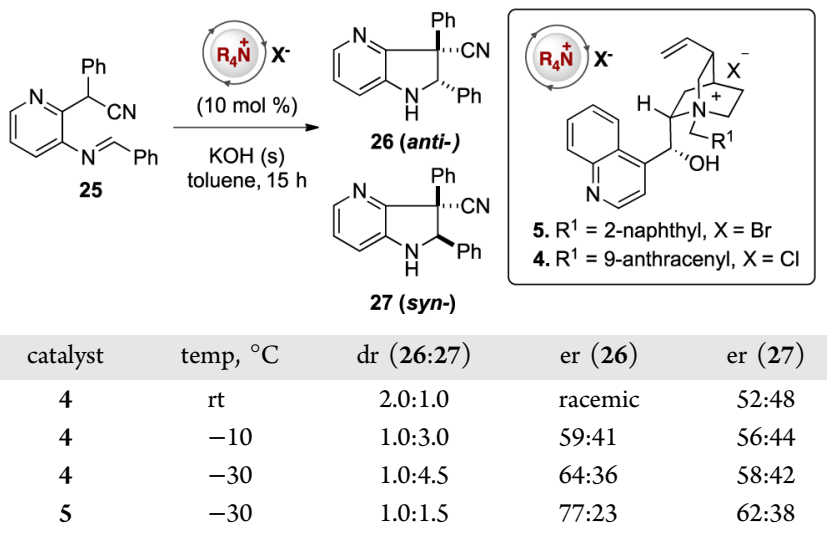

${ }^{a}$ Dr determined by ${ }^{1} \mathrm{H}$ NMR spectroscopy of the crude reaction mixture; er determined by chiral stationary phase HPLC.

Cyclization of $\mathbf{2 5}$ with previously identified cinchonidinium catalyst 4 led to 26 and 27 in significantly lower enantioselectivity than previously observed in the cyclization of malonate-derived substrates such as $\mathbf{1}^{19}$

Further variation of the reaction conditions demonstrated that diastereoselectivity is dependent on the temperature. This led us to suspect that that the cyclization may be reversible under the reaction conditions, with the thermodynamically favored anti-phenyl isomer $\mathbf{2 6}$ predominating at higher temperatures. To test this hypothesis, imine $\mathbf{2 5}$ and pure samples of both product diastereoisomers 26 and 27 were treated with solid $\mathrm{CsOH} \cdot \mathrm{H}_{2} \mathrm{O}$ and TBAHS at different temperatures (Scheme 2). ${ }^{1} \mathrm{H}$ NMR spectroscopic analysis of

Scheme 2. Equilibration Experiments ${ }^{a}$

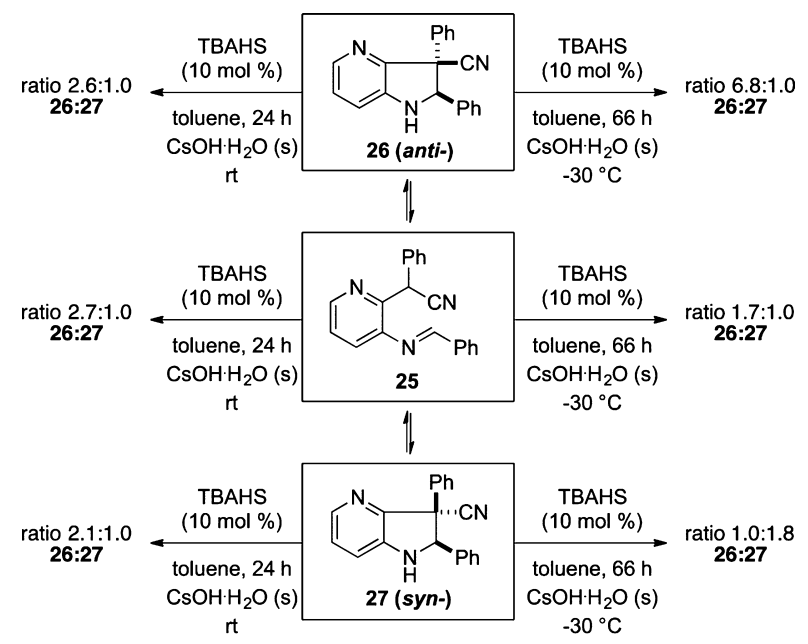

${ }^{a}$ Dr determined by ${ }^{1} \mathrm{H}$ NMR spectroscopy of the crude reaction mixture.

crude reaction mixtures revealed that imine $\mathbf{2 5}$ afforded a diastereoisomeric ratio of 2.7:1.0, 26:27 under these conditions. This ratio of products is close to that observed upon treatment of either of the pure diastereoisomers 26 or 27 under these conditions (2.6:1.0 and 2.1:1.0 26:27 respectively). This is consistent with the cyclization reaction being reversible and the anti-phenyl diastereomer $\mathbf{2 6}$ being the thermodynamic product of the reaction. The diastereoisomeric ratios observed during the equilibration experiments suggest that the ground state energy difference between the products is relatively small. Monitoring the equilibration reaction with TBAHS at $-30{ }^{\circ} \mathrm{C}$ using ${ }^{1} \mathrm{H}$ NMR spectroscopy showed that interconversion between isomers $\mathbf{2 6}$ and $\mathbf{2 7}$ still occurred at this temperature, but at a much slower rate than at rt. This rate of equilibration is slowed further when chiral phase transfer catalysts are employed, suggesting that equilibration has a small role in the enantioselective cyclization but that it is not solely responsible for the poor selectivity observed. Unfortunately, attempts to lower the reaction temperature further to minimize equilibration resulted in incomplete cyclization.

In conclusion we have developed an efficient route to enantiomerically enriched 4-azaindolines bearing aryl or alkyl substituents via a cation-directed asymmetric cyclization, and this route was successfully extended to the synthesis of 6azaindolines. From a mechanistic perspective this reaction is likely to proceed via a kinetically controlled 5-endo-trig mechanism rather than the alternative electrocyclization manifold. This approach is complementary to methods reported for azaindoline synthesis to date and allows access to a diverse range of useful synthetic intermediates.

\section{ASSOCIATED CONTENT}

\section{Supporting Information}

The Supporting Information is available free of charge on the ACS Publications website at DOI: 10.1021/acs.orglett.6b02744.

Full experimental details including ${ }^{1} \mathrm{H},{ }^{13} \mathrm{C}$ and HPLC data (PDF)

X-ray data for 10 (CCDC 1060407), 26 (CCDC 1060405), and 27 (CCDC 1060406) (CIF)

\section{AUTHOR INFORMATION}

\section{Corresponding Author}

*E-mail: martin.smith@chem.ox.ac.uk.

Notes

The authors declare no competing financial interest.

\section{ACKNOWLEDGMENTS}

The European Research Council has provided financial support for this work under the European Community's Seventh Framework Programme (FP7/2007-2013)/ERC Grant Agreement No. 259056. This work was supported by EPSRC (EP/ I003398/1). We gratefully acknowledge the Diamond Light Source for an award of instrument time on I19 (MT7768).

\section{REFERENCES}

(1) (a) Badland, M.; Devillers, I.; Durand, C.; Fasquelle, V.; Gaudillière, B.; Jacobelli, H.; Manage, A. C.; Pevet, I.; Puaud, J.; Shorter, A. J. Tetrahedron Lett. 2011, 52, 5292. (b) Varnes, J. G.; Marcus, A. P.; Mauger, R. C.; Throner, S. R.; Hoesch, V.; King, M. M.; Wang, X.; Sygowski, L. A.; Spear, N.; Gadient, R.; Brown, D. G.; Campbell, J. B. Bioorg. Med. Chem. Lett. 2011, 21, 1402. (c) Piatnitski Chekler, E. L.; Khan, T. A.; Mamidala, R.; Anderson, J. T.; Tangirala, R. S.; Verhoest, P. R.; Gilbert, A. M. Tetrahedron Lett. 2012, 53, 377.

(2) (a) Yakhontov, L. N.; Azimov, V. A.; Lapan, E. I. Tetrahedron Lett. 1969, 10, 1909. (b) Hands, D.; Bishop, B.; Cameron, M.; Edwards, J. S.; Cottrell, I. F.; Wright, S. H. Synthesis 1996, 1996, 877. (c) Walter, H.; Sundermann, C. Heterocycles 1998, 48, 1581. (d) Bacqué, E.; El Qacémi, M.; Zard, S. Z. Org. Lett. 2004, 6, 3671. (e) Fayol, A.; Zhu, J. Org. Lett. 2005, 7, 239. (f) Zheng, X.; Kerr, M. A. 
Org. Lett. 2006, 8, 3777. (g) Bacqué, E.; El Qacémi, M.; Zard, S. Z.

Heterocycles 2012, 84, 291. (h) Nuhant, P.; Allais, C.; Chen, M. Z.;

Coe, J. W.; Dermenci, A.; Fadeyi, O. O.; Flick, A. C.; Mousseau, J. J.

Org. Lett. 2015, 17, 4292.

(3) Danneman, M. W.; Hong, K.-B.; Johnston, J. N. Org. Lett. 2015, 17, 3806.

(4) Métro, T. X.; Fayet, C.; Arnaud, F.; Rameix, N.; Fraisse, P.; Janody, S.; Sevrin, M.; George, P.; Vogel, R. Synlett 2011, 2011, 684.

(5) Bailey, W. F.; Salgaonkar, P. D.; Brubaker, J. D.; Sharma, V. Org. Lett. 2008, 10, 1071.

(6) (a) Watanabe, T.; Oishi, S.; Fujii, N.; Ohno, H. Org. Lett. 2008, 10, 1759. (b) Larionov, E.; Nakanishi, M.; Katayev, D.; Besnard, C.; Kündig, E. P. Chem. Sci. 2013, 4, 1995.

(7) Leroi, C.; Bertin, D.; Dufils, P. E.; Gigmes, D.; Marque, S.; Tordo, P.; Couturier, J. L.; Guerret, O.; Ciufolini, M. A. Org. Lett. 2003, 5, 4943.

(8) Srinivasan, J. M.; Burks, H. E.; Smith, C. R.; Viswanathan, R.; Johnston, J. N. Synthesis 2005, 2005, 330.

(9) (a) Maciver, E. E.; Thompson, S.; Smith, M. D. Angew. Chem., Int. Ed. 2009, 48, 9979. (b) Johnston, C. P.; Kothari, A.; Sergeieva, T.; Okovytyy, S. I.; Jackson, K. E.; Paton, R. S.; Smith, M. D. Nat. Chem. 2015, 7, 171.

(10) Maciver, E. E.; Knipe, P. C.; Cridland, A. P.; Thompson, A. L.; Smith, M. D. Chem. Sci. 2012, 3, 537.

(11) Yin, X.-P.; Zeng, X.-P.; Liu, Y.-L.; Liao, F.-M.; Yu, J.-S.; Zhou, F.; Zhou, J. Angew. Chem., Int. Ed. 2014, 53, 13740.

(12) Initial attempts at imine formation using a large excess of $\mathrm{MgSO}_{4}$ were hampered by undesired racemic cyclization, believed to be due to the acidity of the dehydrating agent. This could be alleviated by using 1.2 equiv of $\mathrm{MgSO}_{4}$ and removing trace amounts of cyclized material by recrystallization. In previous work imines were not isolated to prevent lowering yield during purification, but this approach was found to be deleterious to the er of the cyclization in the azaindoline system. See the Supporting Information for full details.

(13) Substitution of the pyridine ring with a halogen resulted in poor enantioselectivities. These results and the synthesis of the required substrates are detailed in the Supporting Information

(14) CCDC 1060407 (10), 1060405 (26), and 1060406 (27) contain the supplementary crystallographic data for this paper. These data can be obtained free of charge from The Cambridge Crystallographic Data Centre via www.ccdc.cam.ac.uk/data_request/ cif.

(15) Synthesis of the 5-azaindoline isomer was also attempted, but imine formation did not proceed to completion at room temperature and higher temperatures resulted in uncontrolled background cyclization.

(16) For full synthetic details, see the Supporting Information.

(17) In general, imines were isolated in low yields and required elevated temperatures for formation. Electron-rich aldehydes were not generally effective partners in this process, as the imines thus formed were prone to background racemic cyclization (see the Supporting Information for full details).

(18) Sharma, K.; Wolstenhulme, J. R.; Painter, P. P.; Yeo, D.; Grande-Carmona, F.; Johnston, C. P.; Tantillo, D. J.; Smith, M. D. J. Am. Chem. Soc. 2015, 137, 13414.

(19) We also examined pseudoenantiomeric cinchonidine-derived phase transfer catalysts. These gave very similar er and dr values (but the opposite sign of optical rotation). 